\title{
DETECTION RATES OF ROTAVIRUS ANTIGEN FROM DIARRHEAL PATIENTS IN LAO PEOPLE'S DEMOCRATIC REPUBLIC
}

\author{
BOUNNANH PHANTOUAMATH ${ }^{1}$, NOIKASEUMSY SITHIVONG ${ }^{1}$, LAY SISAVATH ${ }^{1}$, KHAMPHYEU MOUNNALATH ${ }^{1}$, \\ KHAMPHENG CHOMLASAK ${ }^{1}$, SITHAT INSISIENGMAY ${ }^{1}$, TETSU YAMASHIRO ${ }^{2}$, and MASAAKI IWANAGA ${ }^{3}$ \\ Accepted 18, February, 2004
}

\begin{abstract}
The detection rate of rotaviruses from diarrheal stools in Lao People's Democratic Republic (Lao PDR) was studied in the period from 1994 to 2003. Rotavirus antigen was detected using latex agglutination kit. The average detection rate was $2.4 \%$, or 18 of 738 cases examined in total. Rotavirus was not detected from 175 cases examined in 1995, 1998, 2000 and 2003, but 8 of 85 cases (9.4\%) examined in 1997 were positive for rotavirus. The detection rate was $6.0 \%$ in the age group younger than 2 years and $0.6 \%$ in the age group older than 2 years. These detection rates were markedly lower than those in neighboring countries such as Vietnam and Thailand.
\end{abstract}

Rotaviruses are a major cause of diarrhea in infants and young children. The infections are also common in adult. Rotavirus infections are frequently seen throughout the year in tropical areas, but they are predominant during the winter season in the temperate zone. On the basis of reported data, the detection rate of rotavirus from pediatric diarrhea is about $30 \%$ on average [1-11]. A high frequency of rotavirus infection has been reported in Vietnam and Thailand, countries neighboring Lao PDR. Some reports show that the detection rate of rotavirus in pediatric diarrhea was 50 to $60 \%$ in Vietnam and 30 to $40 \%$ in Thailand $[3,7,8]$. Although available from many other countries, no data on the detection frequency of rotavirus from diarrheal stools has been reported from Lao PDR. In the present paper, therefore, we present the detection rate of rotavirus from the stools of diarrheal patients in Lao PDR over the past decade.

Stool samples submitted to our Laboratory (Center for Laboratory and Epidemiology, Ministry of Health, Lao PDR) for analysis of enteropathogens from a number of hospitals and clinics in Vientiane were examined. The samples were collected from diarrheal patients in the period from 1994 to 2003. All samples were taken in plastic containers, and a total of 738 stool samples were examined. Rotavirus was detected using a commercially available latex agglutination kit (MICROGEN, Bioproducts LTD., England UK). Watery stools were directly treated with an equal volume of extraction buffer included in the kit. Muddy stools were first diluted double with normal saline solution and
$100 \mu \mathrm{l}$ of the diluent was treated with $100 \mu \mathrm{l}$ of extraction buffer. The treated samples were centrifuged at 10,000 rpm for $5 \mathrm{~min}$. A drop of the sensitized latex solution was placed at 3 places on the special sheet (black background) for the agglutination test. A drop of positive and negative control solution was added to the first and second latex, respectively, and a drop of stool supernatant was added to the third latex. Each sample was mixed well using a toothpick and then gently tilted several times. Agglutination was visually observed.

The detection rate of rotavirus from diarrheal stools was generally very low. Only 18 of 738 cases examined over the past 10 years were positive for rotavirus $(2.4 \%)$. No positive case was found among the 175 cases examined in 1995, 1998, 2000 and 2003. The highest positive rate was observed in the 1997 samples, but this was still lower than $10 \%$ (Table 1). Rotavirus was mainly detected in the younger age group, a finding consistent with other reports. In the age group younger than 2 years, 15 of 250 cases examined $(6.0 \%)$ were positive, but in age group older than 2 years, the positive rate was $0.6 \%$, or 3 of 488 , which was one-tenth that of the former group (Table 2). In spite of this fact, high infection rates such as 30 to $60 \%$ of pediatric diarrhea were reported in Vietnam and Thailand [3,7,8] countries neighboring Lao PDR. Although the reason for the low infection rate in Lao PDR is unclear, population density, which is markedly lower in Lao PDR than Vietnam and Thailand, may influence the infection rate. If person to person infection is the main infection route of rotavirus,

1) Center for Laboratory and Epidemiology, Ministry of Health, Vientiane, Lao PDR

2) Department of Social and Environmental Medicine, Institute of Scientific Research, Oita University, Oita, Japan

3) Division of Bacterial Pathogenesis, Department of Microbiology, Graduated School of Medicine, University of the Ryukyus, Okinawa, Japan 
Table 1. Detection rate by year

\begin{tabular}{ccc}
\hline Year & No. examined & No. positive $(\%)$ \\
\hline 1994 & 84 & $1(1.1)$ \\
1995 & 67 & 0 \\
1996 & 113 & $2(1.8)$ \\
1997 & 85 & $8(9.4)$ \\
1998 & 24 & 0 \\
1999 & 32 & $1(3.1)$ \\
2000 & 21 & 0 \\
2001 & 84 & $1(1.1)$ \\
2002 & 165 & $5(3.0)$ \\
2003 & 63 & 0 \\
\hline Total & 738 & $18(2.4)$
\end{tabular}

Table 2. Distribution by age group

\begin{tabular}{ccc}
\hline Age group (year) & No. examined & No. positive (\%) \\
\hline $1>$ & 143 & $9(6.2)$ \\
$1-2$ & 107 & $6(5.6)$ \\
$2-5$ & 59 & 0 \\
$5-15$ & 42 & $1(2.3)$ \\
$15<$ & 387 & $2(0.5)$ \\
Total & 738 & $18(2.4)$ \\
\hline
\end{tabular}

population density may play an important role in the spreading of the disease. According to a report in 1994 [4], rotavirus infection rate among children was $0.96 \%$ (16 of $1,668)$ in New Caledonia where the population density is lower than in Lao PDR. The detection method used in the present study may also have contributed to the low detection rate. A comparative study on the ability of commercially available ELISA kits and RPLA kits to detect rotavirus in stools revealed that the sensitivity was about $88 \%$ in ELISA and $70 \%$ in RPLA 〔12〕. The studies in Thailand and Vietnam used ELISA while the present study in Lao PDR used RPLA to detect rotavirus. Most samples in the present study were collected in the dry season, and there seems to be some seasonal variation on the detection rate. Rotavirus is antigenicaly classified into 5 groups, A to E. These groups have independent RNA. Type A rotavirus is the most prevalent in humans throughout the world, but infections with type B and C have also been reported $[9,10]$. Therefore, non-type A rotavirus should also be considered when discussing the infections in Lao PDR.

The present paper briefly reported the distribution of rotavirus in Lao PDR summarizing the accumulated laboratory data. Since the epidemiological information from this country has been very limited, the data will contribute to discussions on the worldwide epidemiology of rotavirus infection.

\section{REFERENCE:}

1 . Albert MJ, Faruque ASG, Faruque SM, Sack RB, and Maharanabis D. Case-control study of enteropathogens associated with childhood diarrhea in Dhaka, Bangladesh. J Clin Microbiol 1999; 37: 3459-64

2. Bol K, Castagnaro N, Borsa A, Espul C, Fay O, Fabri A, Grinstein S, Miceli I, Matson DO, and Gomez JA. Surveillance for rotavirus in Argentina. J Med Virol 2001; 65: 190 $-8$

3 . Echeverria P, Hoge CW, Dodhidatta L, Tungtaem C, Herrmann J, Imlarp S, and Tamura K. Etiology of diarrhea in a rural community in western Thailand: importance of enteric viruses and enterovirulent Escherichia coli. J Infect Dis 1994; 169: 916-9

4 . Germani Y, Morillon M, Begaud E, Dubourdieu H, Costa R, and Thevenon J. Two-year study of endemic enteric pathogens associated with acute diarrhea in New Caledonia. J Clin Microbiol 1994; 32: 1532-6

5 . Iwanaga M, Nakasone N, Nakamura S, Wasito EB, Soeparto P, Sudarmo SM, Soewandojo E, and Ranuh IGNG. Etiologic agent of diarrheal diseases in Surabaya, Indonesia. Jpn J Trop Med Hyg 1993; 21: 143-7

6 . Kim KH, Shu IS, Kim JM, Kim CW, and Cho YJ. Etiology of childhood diarrhea in Korea. J Clin Microbiol 1989; 27: 1192-6

7 . Nguyen THT, Nga TH, Van TT. Rotavirus surveillance in children with acute diarrhea in Vietnam. In Proceeding, International Seminar on emerging and re-emerging infectious diseases. 2000; November 16-18, Institute of Tropical Medicine, Nagasaki University, Japan

8 . Pipittajan P, Kasempimolporn S, Ikegami N, Akatani K, Wasi C, and Sinarachatanant P. Molecular epidemiology of rotaviruses associated with pediatric diarrhea in Bangkok, Thailand. J Clin Microbiol 1991; 29: 617-24

9 . Sanchez-Fauquier A, Roman E, Colomina J, Wilhelmi I, Glass RI, and Jiang B. First detection of group C rotavirus in children with acute diarrhea in Spain. Arch Virol 2003; 148: 399-404

10 . Sanekata T, Ahmed MU, Kader A, Taniguchi K, Kobayashi N. Human group B rotavirus infections cause severe diarrhea in children and adults in Bangladesh. J Clin Microbiol 2003; 41: 2187-90

11. Scaletsky ICA, Fabbricotti SH, Carvalho LB, Nunes CR. Maranhao HS, Morais MB, and Fagundes-Neto U. Diffusely adherent Escherichia coli as a cause of acute diarrhea in young children in Northern Brazil: a case-control study. J Clin Microbiol 2002; 40: 645-8

12. Gilchrist MJ, Bretl TS, Moultney K, Knowlton DR, and Ward RL. Comparison of seven kits for detection of rotavirus in fecal specimens with a sensitive specific enzyme immunoassay. Diagn Microbiol Infect Dis 1987; 8: 221-8 